\title{
Prediction of water breakthrough time in horizontal Wells in edge water condensate gas reservoirs
}

\author{
Huang QuanHua ${ }^{1}$, Lin XingYu*1 \\ ${ }^{1}$ Petroleum engineering school, Southwest petroleum university, Chengdu, Sichuan, 610500, china
}

\begin{abstract}
Horizontal Wells are often used to develop condensate gas reservoirs. When there is edge water in the gas reservoir, it will have a negative impact on the production of natural gas. Therefore, reasonable prediction of its water breakthrough time is of great significance for the efficient development of condensate gas reservoirs.At present, the prediction model of water breakthrough time in horizontal Wells of condensate gas reservoir is not perfect, and there are mainly problems such as incomplete consideration of retrograde condensate pollution and inaccurate determination of horizontal well seepage model. Based on the ellipsoidal horizontal well seepage model, considering the advance of edge water to the bottom of the well and condensate oil to formation, the advance of edge water is divided into two processes. The time when the first water molecule reaches the bottom of the well when the edge water tongue enters is deduced, that is, the time of edge water breakthrough in condensate gas reservoir.The calculation results show that the relative error of water breakthrough time considering retrograde condensate pollution is less than that without consideration, with a higher accuracy. The example error is less than $2 \%$, which can be effectively applied to the development of edge water gas reservoir.
\end{abstract}

\section{Introduction}

Edge water often causes water invasion to condensate gas reservoir, which affects gas reservoir recovery. At present, there are many studies on conventional gas reservoir models of edge water. In $1983, \mathrm{KUO}^{[1]}$ predicted the water breakthrough time of edge water and bottom water gas reservoirs based on the seepage law of fluids in porous media.In 2017, $\mathrm{GUO}^{[2]}$ established a water breakthrough time prediction model for high sulfur gas reservoirs.In 2011, Wu Keliu ${ }^{[3]}$ established a prediction model of water breakthrough time for edge water gas reservoirs considering retrograde condensate effect, which provided a theoretical basis for controlling water breakthrough time.In 2016, we ${ }^{[4]}$ analyzed the water breakthrough time of bottom water gas reservoirs with baffles. In 2018, Ming Ruiqing ${ }^{[5-6]}$ established a water breakthrough time prediction model for the edge water condensate gas reservoir, but the horizontal well seepage model was circular, which was not consistent with the actual situation.In 2019, we ${ }^{[7-8]}$ established a horizontal gas well water breakthrough model with consideration of highspeed non-Darcy effect. The model adopted an ellipsoidal seepage model, which was successfully applied to the prediction of water breakthrough time of high-yielding horizontal Wells.In 2020, we [9] also established a prediction model for water breakthrough time in vertical Wells considering edge water condensate gas reservoirs.

Retrograde condensate pollution exists in condensate gas reservoirs, and the fluid flow rate near the well zone increases because the condensate occupies the pore volume, thus accelerating the advance of edge water. Therefore, although the retrograde condensate area of condensate gas reservoirs is limited, the influence of condensate oil on the water breakthrough time cannot be ignored. In this paper, a model for predicting water breakthrough time of edge water condensate gas reservoir is developed by taking into account such factors as gas flow degree ratio, bound water saturation, residual gas saturation, condensate oil saturation, distance between gas well and edge water, and horizontal well length.

\section{Model}

As shown in Fig. 1, the initial gas water boundary of edge water condensate gas reservoir is approximately treated as a straight line, which is recorded as y. A horizontal well producing at the distance o from $\mathrm{Y}$, and the horizontal section length of the horizontal well was L. According to the relevant seepage mechanics theory, the ellipsoidal model is adopted as the horizontal well seepage model. And according to the existing research results of horizontal well water flooding in edge water reservoirs, water invasion in horizontal Wells is pushed forward by water tongue. Therefore, when the gas well begins to produce, the gas-water interface starts to push toward the bottom of the well, and the gas-water interface becomes surface $Y^{\prime}$. At the same time, because of gas reservoir is condensate gas reservoir, when the pressure is lower than dew point pressure, formation of precipitation of

\footnotetext{
* Corresponding author: cnlinxingyu@163.com
} 
condensate oil. At the same time, there is a gas condensate advance interface, which is record as $\mathrm{X}$, when bottom hole pressure is lower than dew point pressure, the interface from the bottom hole to the edge water area. Considering the horizontal seepage characteristics and the characteristics of the pressure in the horizontal section of the wellbore is the same, this model will be treated as interface $\mathrm{x}$ approximate to linear interface.

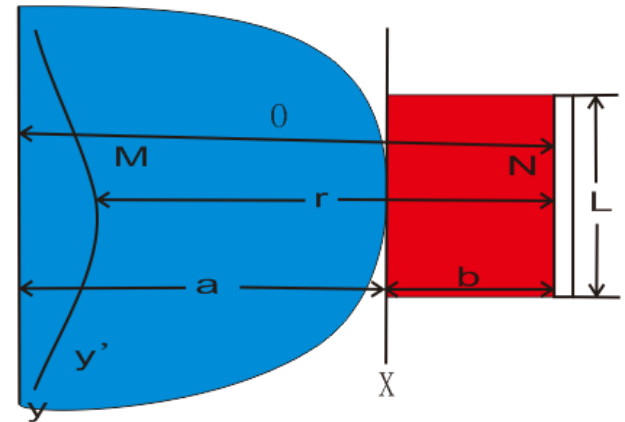

Figure 1 edge water propelling of horizontal wells

\section{The formulas}

Based on the above seepage law, it is assumed that $\mathrm{M}$ is the water tongue thrust point, $\mathrm{N}$ is the central position of the horizontal perforation section, and the distance between $\mathrm{M}$ and $\mathrm{N}$ is R.On the basis of satisfying the basic seepage law of gas-water two-phase, the following assumptions are made for the derivation process :(1) the reservoir is equithick and homogeneous, and the water phase drives the gas phase by piston displacement.(2) Capillary force and gravity are not considered.(3) In the seepage process, the viscosity and density of gas and water are constant.(4) The three phase seepage of oil, gas and water conforms to Darcy's Law.

From interface $\mathrm{Y}$ to interface $\mathrm{X}$, the time of edge water propulsion is tbt1, and from interface $\mathrm{X}$ to wellbore, the time of edge water propulsion is tbt2.Therefore, the water breakthrough time of edge water condensate gas reservoir can be expressed as:

$$
t_{\mathrm{bt}}=t_{\mathrm{bt} 1}+t_{\mathrm{bt} 1}
$$

According to the gas-water two-phase seepage law, considering the Darcy flow effect of gas, the gas-water two-phase motion equation can be written as follows:

$$
\begin{aligned}
& \frac{\mathrm{d} p_{\mathrm{g}}}{\mathrm{d} r}=\frac{u_{\mathrm{g}} v_{\mathrm{g}}}{k_{\mathrm{g}}} \\
& \frac{\mathrm{d} p_{\mathrm{w}}}{\mathrm{d} r}=\frac{u_{\mathrm{w}} v_{\mathrm{w}}}{k_{\mathrm{w}}}
\end{aligned}
$$

Regardless of capillary force, the pressure gradient of gas phase and water phase is equal at the gas-water interface. There are:

$$
\left.\frac{\mathrm{d} p_{\mathrm{g}}}{\mathrm{d} r}\right|_{y^{\prime}}=\left.\frac{\mathrm{d} p_{\mathrm{w}}}{\mathrm{d} r}\right|_{y^{\prime}}
$$

Equations (2) and (3) are substituted into Equation (4), and the units in the formula are unified according to the practical system units of the mine, so as to obtain the seepage velocity of the aqueous phase

$$
v_{\mathrm{w}}=\frac{v_{\mathrm{g}}}{M_{\mathrm{gw}}}
$$

Where,

$$
M_{\mathrm{gw}}=\frac{K_{g} / u_{\mathrm{g}}}{K_{\mathrm{w}} / u_{\mathrm{w}}}
$$

Where, Mgw - Gas-water flow ratio, decimal;pgGas phase pressure, MPa;pw-Water phase pressure, $\mathrm{MPa} ; \mathrm{r}$ - The distance that the water quality point moves to the well, $\mathrm{m} ; \mu \mathrm{g}$ - Viscosity of gas phase, $\mathrm{mPa} \cdot \mathrm{S} ; \mathrm{vg}$ Gas phase velocity, m/d;uw-Water phase velocity, $\mathrm{m} / \mathrm{d} ; \mathrm{Kg}$ - Gas permeability , $\mathrm{mD}$; $\mathrm{Kw}$-Water permeability, $\mathrm{mD} ; \rho \mathrm{g}$ - The density of the gas phase, $\mathrm{g} / \mathrm{cm} 3$; Kgwi-Gas permeability under bounded water saturation Swi, mD; Kwgr-Water permeability under residual gas saturation $\mathrm{Sgr}, \mathrm{mD}$ 。

In porous media, considering the influence of porosity, original irreducible water saturation and residual gas saturation, the distance that water quality point moves to the center of horizontal perforation section $\mathrm{N}$ in $\mathrm{dt}$ time is :

$$
\mathrm{d} r=v_{\mathrm{w}} \mathrm{d} t /\left[\varphi\left(1-S_{\mathrm{wi}}-S_{\mathrm{gr}}\right)\right]
$$

By deforming and integrating equation (6), the breakthrough time of water quality point from the initial gas-water interface to the bottom hole can be obtained:

$$
t_{\mathrm{bt} 1}=\varphi\left(1-S_{\mathrm{wi}}-S_{\mathrm{gr}}\right) \int_{a}^{a+b} \frac{M_{g w}}{v_{\mathrm{g}}} d r
$$

Assume that the vent zone of a horizontal well is elliptic. The equipotential surface at point $\mathrm{M}$ on the front edge of water drive is also elliptic, the size of its long half axis is $\mathrm{r}+\mathrm{L} / 2$ and the short half axis is r.It can be known that the seepage velocity of the gas phase can be expressed as:

$$
v_{\mathrm{g}}=\frac{q_{\mathrm{g}} B_{\mathrm{g}}}{(2 \pi r+2 L) h}
$$

Where, qg-Gas well production, $\mathrm{m} 3 / \mathrm{d} ; \mathrm{Bg}$ - The volume coefficient of natural gas, decimal; $\mathrm{h}$ - Reservoir thickness, m; L-Horizontal section length of horizontal well, m。

Substituting Equation (8) into Equation (7) can be obtained;

$$
t_{\mathrm{bt} 1}=\varphi\left(1-S_{\mathrm{wi}}-S_{\mathrm{gr}}\right) \int_{b}^{a+b} \frac{1}{\frac{A}{2 \pi r+2 L}} d r
$$

Where, $A=\frac{q_{\mathrm{g}} B_{g}}{h M_{g w}}$

Twice substitution integral of Equation (9) can be solved as follows:

$t_{\mathrm{bt} 1}=\varphi\left(1-S_{\mathrm{wi}}-S_{\mathrm{gr}}\right)\left[\frac{\pi(a+b)^{2}+2(a+b) L-\left(\pi b^{2}+2 b L\right)}{A}\right]$

Equation (10) refers to the time when the edge water advance of horizontal well just affected the condensate oil region in the edge water gas reservoir. 


$$
\begin{gathered}
t_{\mathrm{bt} 2}=\varphi\left(1-S_{\mathrm{wi}}-S_{\mathrm{gr}}-S_{o c}\right) \int_{0}^{b} \frac{M_{g w}}{v_{\mathrm{g}}} d r \\
t_{\mathrm{bt} 2}=\varphi\left(1-S_{\mathrm{wi}}-S_{\mathrm{gr}}-S_{o c}\right) \int_{0}^{b} \frac{1}{\frac{A}{2 \pi r+2 L}} d r
\end{gathered}
$$

According to the Muskat condensate saturation variation formula, the blocking radius to achieve critical flow saturation is derived:

$$
\begin{array}{r}
b=101 \frac{q_{g}}{h} \sqrt{\frac{\mu_{g} Z T y t_{\mathrm{bt} 1}}{S_{o c} \phi K p_{R}}} \\
a+b=o
\end{array}
$$

Therefore, the formula of water breakthrough time in horizontal Wells of condensate gas reservoirs can be obtained:

$$
\begin{aligned}
& t_{\mathrm{bt}}=\varphi\left(1-S_{\mathrm{wi}}-S_{\mathrm{gr}}\right)\left[\frac{\pi(a+b)^{2}+2(a+b) L}{A}\right] \\
& -\varphi S_{o c}\left[\frac{\pi b^{2}+2 b L}{A}\right]
\end{aligned}
$$

In combination with equations (10), (13), (14) and (15), the water breakthrough time of horizontal Wells in condensate gas reservoirs can be solved.

\section{Calculation}

A side water vapor have 1 mouth production of horizontal well thermal fluid activity, reservoir thickness $h=10 \mathrm{~m} \mathrm{~m}$, porosity $\varphi=0.052$, irreducible water saturation $\mathrm{Swi}=0.43$, residual gas saturation $\mathrm{Sgr}=0.11$, the critical condensate saturation $\mathrm{Soc}=0.1$, the gas phase permeability under the irreducible water saturation Swi Kgwi $=0.217 \mathrm{mD}$, residual gas saturation water phase permeability under the Sgr Kwgr $=0.364 \mathrm{mD}$, gas phase permeability $\mathrm{Kg}=9.81 \mathrm{mD}$, the density of the gas phase $\rho g=0.2829 \mathrm{~g} / \mathrm{cm} 3$, gas volume coefficient of $\mathrm{Bg}=0.00313 \mathrm{~m} 3 / \mathrm{m} 3$, Gas viscosity $\mu \mathrm{g}=0.0348 \mathrm{mPa} \cdot \mathrm{s}$, water viscosity $\mu \mathrm{w}=0.39 \mathrm{mPa} \cdot \mathrm{s}$. The horizontal section length of the horizontal wellL $=480 \mathrm{~m}$, and the central position of the horizontal section is $450 \mathrm{~m}$ from the initial gas-water boundary. See the average production before waterqg $=560000 \mathrm{~m} 3 / \mathrm{d}$. The daily gas and water production curves of this horizontal well are shown in Figure 2.As can be seen from Figure 2, the well was put into production on January 8, 2010. On June 10, 2012, the gas well began to see water, and then the production declined rapidly. The water breakthrough time was $884 \mathrm{~d}$.The schematic diagram of condensate blocking radius (FIG. 3) can be calculated according to the Muskat formula, and the linear regression can be used to reverse the time TBT1 when the condensate oil meets the edge water.

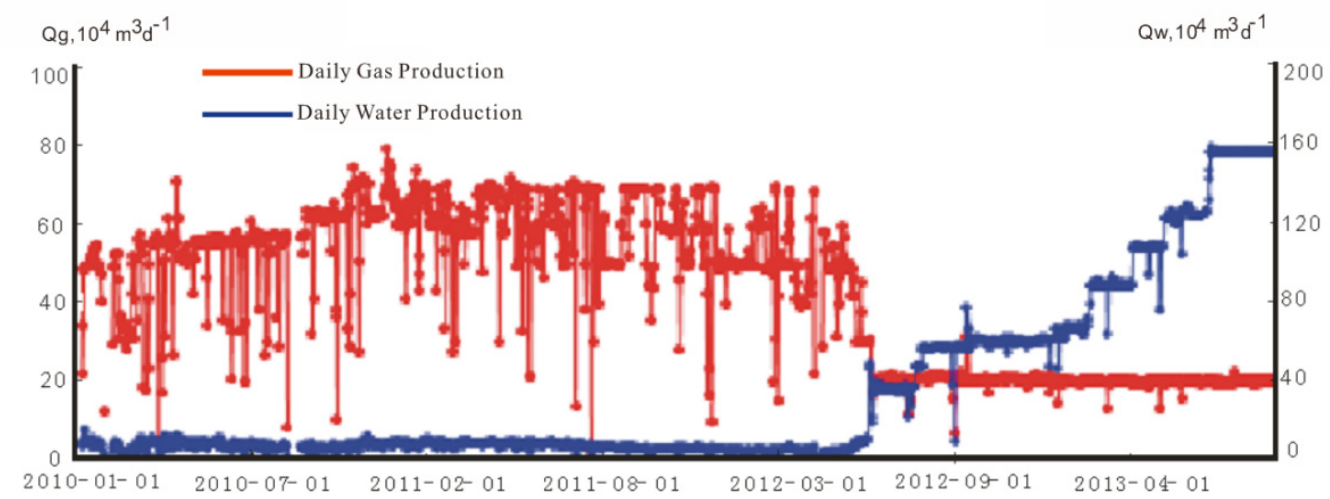

Figure 2 Production performance data of gas well

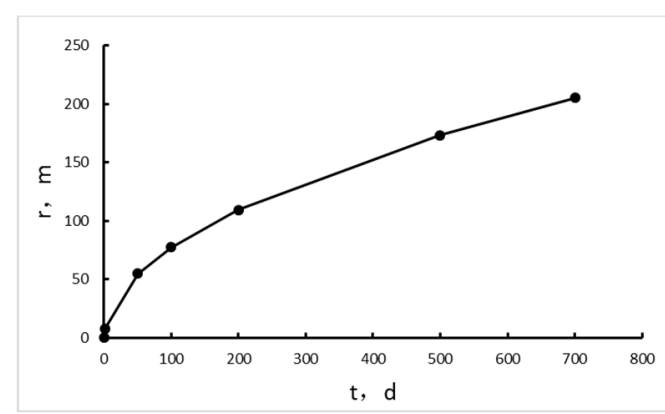

Figure 3 Advance distance of condensate blocking radius

With the above parameters taken into account, the water breakthrough time of horizontal wells without considering reverse condensate pollution is 935 days, and the error is $5.77 \%$ compared with the actual situation. The results show that the water breakthrough time of horizontal well considering retrograde condensate pollution is $872 \mathrm{~d}$, and the error is $1.34 \%$ compared with the actual situation. According to the analysis, when the production days of the well is 698 days, the condensate meets the edge water, the distance of condensate advancing is $178.42 \mathrm{~m}$, and the influence days of condensate on edge water is 62.51 days. The prediction accuracy of water breakthrough time is improved by $4.43 \%$ when considering the influence of condensate oil, and the influence of condensate oil can not be ignored in the prediction of water breakthrough time of condensate gas reservoir.

Since the condensate oil reduces the pore volume, it further improves the seepage velocity of water and gas in the near well zone, and accelerates the water breakthrough in condensate gas reservoir. Therefore, in the production, it is necessary to ensure that the bottom hole pressure is not too low to reduce the condensate precipitation rate for delaying the breakthrough time of edge water in gas wells.

At the same time, because the gas wells used in the case are high-yield horizontal wells, and the formation pressure is high, there will be start-up pressure gradient, water lock effect and oil lock effect in the process of fluid 
seepage, which will increase the seepage resistance of water molecules in the pores, reduce the seepage velocity of water molecules in the pores, and delay the breakthrough time of edge water; in the condensate seepage area, the actual condensate saturation near the well is higher than the critical flow saturation, it will also increase the resistance to the movement of edge water. Therefore, there are still some errors in the breakthrough time of edge water calculated by this formula.

\section{Conclusion}

By analyzing the advance of edge water in condensate gas reservoir and considering the retrograde condensate pollution, we establish a water breakthrough prediction model for horizontal wells in condensate gas reservoirs. The ellipsoidal seepage model of horizontal wells is adopted, and the gas water mobility ratio is used to convert the natural gas seepage velocity into the formation water seepage velocity, and the calculation formula of water breakthrough time is derived. This method can also calculate the time and distance when edge water and condensate meet, which is helpful to understand the actual performance of edge water breakthrough in condensate gas reservoir. The reliability of the formula is verified by case analysis, which can effectively improve the prediction accuracy of water breakthrough time. It is considered that the influence of condensate oil can not be ignored in the prediction of water breakthrough time in horizontal wells.

\section{Acknowledgments}

Supported by the National Major Science and Technology Project "Research on percolation Mechanism and Development Technology Policy of Thick Heterogeneous Gas Reservoirs" (No. :2016ZX05027-004-005).

\section{Reference}

1. KUO M C T. (1983) A simplified method for water coning predictions. SPE 12067.

2. Guo X, Wang P, Liu J, Song G et al. (2017)Gas-well water breakthrough time prediction model for highsulfur gas reservoirs considering sulfur deposition. Journal of Petroleum Science and Engineering. 157: 999-1006

3. Wu K L, Li XF, Zhang GT, et al. (2011)A new method for prediction of water breakthrough time of edgewater condensate gas reservoir considering retrograde condensation .Science Technology and Engineering, 11(19):4574-4577.

4. Huang Q H, Lu Y, Fu YH, et al. (2016)An approach to predict water breakthrough time of gas reservoirs with bottom water in consideration of non-Darcy flow. Science Technology and Engineering, 14: 137-140.

5. Ming R Q, He HQ, Hu QF. (2018)A new method for prediction of water breakthrough time of bottom water condensate gas reservoir. Special Oil \& Gas
Reservoirs, 05:1-7.

6. Ming R Q, He HQ, Hu QF, et al. (2018)A new prediction model for water breakthrough time in highyielding Wells of edge-water condensate gas reservoir. Special Oil \& Gas Reservoirs, 25(02):76-79.

7. Huang Q H, Lin XY, Tong K.(2018) An Approach to Predict Water Breakthrough Time for Horizontal Wells in Gas Reservoirs with Edge-Water in Consideration of Non-Darcy Flow. GMEE 2018.

8. Huang Q H, Lin XY, Tong K.(2019) Prediction of water breakthrough time in horizontal Wells of nonDarcy Seepage flow marginal water gas reservoirs, 31(01):147-152.

9. Huang Q H, Lin XY, Xu QL; et al. (2020) A New Method for Predicting Water Breakthrough Time in the Edge Water Condensate Gas Reservoir. IOP Conference Series: Earth and Environmental Science.526: 012126. 